\title{
Patient preferences and satisfaction in the treatment of rheumatoid arthritis with biologic therapy
}

This article was published in the following Dove Press journal:

Patient Preference and Adherence

16 November 2009

Number of times this article has been viewed

\section{Jennifer L Barton}

Division of Rheumatology, University of California San Francisco,

San Francisco, California, USA
Correspondence: Jennifer L Barton Division of Rheumatology, UCSF, Box 0500, 374 Parnassus Avenue, San Francisco, CA 94I43, USA $\mathrm{Tel}+\mathrm{I}(4 \mathrm{I} 5)$ 476-4732

Fax + I (4I5) 476-9370

Email jennifer.barton@ucsfmedctr.org
Abstract: Significant advances in the treatment of rheumatoid arthritis (RA) have been made over the past 10 years with the introduction of biologic therapies, such as the TNF inhibitors. With these medications, many patients with RA have seen significant improvement in symptoms, function, and quality of life. However, with the introduction of the biologics, decision-making for this chronic disease that affects up to $1 \%$ of the population has become even more complex. Patient preferences for mode and frequency of administration, and for certain risks vs benefits as well as medication beliefs are central to uptake and adherence to these medications. This review examines the current literature on patient satisfaction, adherence, and preference for biologic therapy in RA.

Keywords: rheumatoid arthritis, patient preference, adherence, biologics

\section{Introduction}

Rheumatoid arthritis (RA) affects approximately $0.5 \%$ to $1 \%$ of the population and causes significant morbidity and early mortality. ${ }^{1,2}$ The introduction of biologic therapies over the past 10 years has lead to significant improvement in outcomes for patients with RA, including clinical symptoms, quality of life, and function. ${ }^{3}$ While these newer therapies have been shown to be equally efficacious when compared to traditional disease-modifying anti-rheumatic drugs (DMARDs) such as methotrexate, ${ }^{4-9}$ they present different choices for route of administration, increased or different toxicities, and higher financial costs, all of which may impact patient preference and adherence.

Assessing patient preferences for treatment in RA is a necessary step toward improving outcomes by ensuring satisfaction and adherence. Health disparities in outcomes and utilization in RA have been reported by race/ethnicity, education level, and insurance status. ${ }^{10-14}$ Another possible proposed mechanism for these disparities is differences in patient preferences. ${ }^{15}$ In 2003, the Institute of Medicine published a report entitled Unequal Treatment: Confronting Racial and Ethnic Disparities in Health Care which defined patient preferences as "choices regarding healthcare that are based on a full and accurate understanding of treatment options". ${ }^{16}$ In any assessment of patient preference, it is essential that patients have been fully informed of risks and benefits for a particular treatment. Another important factor for effective, informed decision-making is trust in the physician, since trust has been shown to have a greater effect on the patient's confidence in a DMARD decision than his or her DMARD-specific knowledge, disease-related factors or demographics. ${ }^{17}$ While knowledge and trust have not been extensively examined in the context of 
studying patient preferences for treatment in RA, it is important to keep sight of these concepts when reviewing the literature.

The objectives of this review are to examine the current literature on patient preferences, satisfaction, and adherence to the biologic DMARDs (limited to the TNF inhibitors) for RA treatment.

\section{Overview of treatment of RA}

The main treatment goals for RA include control over pain and inflammation, halting progression of bony erosions, and improving function. ${ }^{4}$ Therapy for RA has undergone significant evolution since the introduction of biologic therapies in 1998. The course of the disease can vary from person to person, and can also vary in intensity within each patient which requires tailored, individualized therapy. Both traditional (or non-biologic DMARDs such as methotrexate) as well as the biologic DMARDs require frequent monitoring for toxicity as well as clinical response, necessitating frequent visits with a rheumatologist. Given the spectrum of disease activity and manifestations across individuals as well as the ever growing armamentarium of RA medications, there exists no standardized algorithm for treatment. As a guide for clinicians, the American College of Rheumatology (ACR) published recommendations in 2008 for the initiation of non-biologic and biologic DMARDs for the treatment of RA using various algorithms based on duration of disease, presence of poor prognostic factors (eg, rheumatoid factor positive, presence of erosions on X-ray) and level of disease activity. ${ }^{18}$ The mode of delivery for the biologic DMARDs (intravenous or subcutaneous injection) and the frequency of administration varies, introducing additional variables and choices for patients (Table 1).

Because treatment options, toxicities and mode of delivery vary, it is essential that patterns of adherence, patient preference and satisfaction for therapy in RA are examined.

\section{Patient satisfaction with medications in RA}

The following section summarizes 6 studies which report on some aspect of satisfaction or expectation of therapy in RA. Given that no standard, routinely used measure of satisfaction exists in the rheumatology literature, no set criteria for defining satisfaction was applied to the studies below. The methods for ascertaining satisfaction across studies was not uniform, and ranged from qualitative methods in 2 studies (using focus groups) (19,20 $^{10}$ the use of questionnaires in the

Table I Biologic DMARDS - route of administration, dose, cost and year introduced

\begin{tabular}{|c|c|c|c|c|c|c|}
\hline \multirow{2}{*}{$\begin{array}{l}\text { Drug name } \\
\text { Non-biologic DMARDs - oral }\end{array}$} & \multirow[t]{2}{*}{ Brand name } & \multirow[t]{2}{*}{ Dose $^{2}$} & \multirow[t]{2}{*}{ Frequency } & \multicolumn{2}{|c|}{ Price per month ${ }^{3}$} & \multirow[t]{2}{*}{ Year' $^{\prime}$} \\
\hline & & & & Generic & Brand & \\
\hline \multirow[t]{3}{*}{ Methotrexate } & Rheumatrex & $7.5 \mathrm{mg}$ & once weekly & $\$ 40$ & $\$ 45$ & 1988 \\
\hline & Trexall & $15 \mathrm{mg}$ & once weekly & $\$ 80$ & $\$ 90$ & \\
\hline & & $20 \mathrm{mg}$ & once weekly & $\$ 105$ & $\$ 120$ & \\
\hline \multicolumn{7}{|c|}{ Biologic DMARDs - subcutaneous } \\
\hline Adalimumab & Humira & $40 \mathrm{mg}$ & every 2 weeks & NA & $\$ 1,585$ & 2002 \\
\hline Anakinra & Kineret & $100 \mathrm{mg}$ & daily & NA & $\$ 1,445$ & 2001 \\
\hline \multirow[t]{2}{*}{ Etanercept } & Enbrel & $25 \mathrm{mg}$ & twice weekly & NA & $\$ 1,585$ & 1998 \\
\hline & & $50 \mathrm{mg}$ & once weekly & NA & $\$ 1,585$ & \\
\hline \multicolumn{7}{|l|}{ Biologic DMARDs - intravenous } \\
\hline \multirow[t]{3}{*}{ Abatacept } & Orencia & $500 \mathrm{mg}$ & every 4 weeks & NA & $\$ 1,080$ & 2005 \\
\hline & & $750 \mathrm{mg}$ & every 4 weeks & NA & $\$ 1,620$ & \\
\hline & & $1000 \mathrm{mg}$ & every 4 weeks & NA & $\$ 2,160$ & \\
\hline \multirow[t]{3}{*}{ Infliximab } & Remicade & $3 \mathrm{mg} / \mathrm{kg}$ & every 8 weeks & NA & $\$ 730$ & 1999 \\
\hline & & $6 \mathrm{mg} / \mathrm{kg}$ & every 8 weeks & NA & $\$ 1,465$ & \\
\hline & & $10 \mathrm{mg} / \mathrm{kg}$ & every 8 weeks & NA & $\$ 2,440$ & \\
\hline Rituximab & Rituxan & 1000 mg & 2 weeks apart, 2 doses & NA & $\$ 1,015$ & 2006 \\
\hline
\end{tabular}

Notes: 'Indicated year FDA approved for use in rheumatoid arthritis; Sources: www.fda.gov if not otherwise cited.

${ }^{2}$ Doses representative of those used in research studies or typical for RA.

${ }^{3}$ Average Wholesale Price (US\$) from Drug Topics Red Book, 2007. Price does not include infusion-related expenses.

Abbreviations: DMARDs, disease-modifying antirheumatic drugs; NA, not available as generic.

Adapted from Rheumatoid Arthritis Medicines:A Guide for Adults. AHRQ Pub. No. 08-EHC004-2A. April 2008. Agency for Healthcare Research and Quality. Rockville, MD.49 Used with permission. http://effectivehealthcare.ahrq.gov 
remaining 4 studies. ${ }^{21-24}$ Only one paper reported a rigorous method for developing questions about satisfaction with treatment. ${ }^{21}$ Carbonell and Badia described an initial literature search, compilation of questions, review by four experts for comprehension and applicability, followed by a second version of the questions which were then piloted in 14 patients and refined into the final questionnaire. ${ }^{21}$

Kjeken et al used both closed and open-ended questions in their study of over 1000 Norwegian RA patients' satisfaction with care and found that $68 \%$ were very or somewhat satisfied with the health care they received while only $8 \%$ were somewhat or very dissatisfied. ${ }^{22}$ They also noted that those patients who had a high level of involvement in their care were more likely to be satisfied (91\% satisfied in the high involvement group vs $61 \%$ satisfied in the low involvement group). ${ }^{22}$ In terms of identifying predictors of unmet expectations among patients with rheumatic diseases, Rao and colleagues performed a longitudinal study of 177 subjects (39\% with RA) in the US using a series of 6 questions. ${ }^{23}$ They found that $33 \%$ of patients reported at least one unmet expectation after a clinic visit with the most common reasons being unfulfilled expectations for information (47\%), medication changes (31\%) and physician examination (29\%). Among those patients with unmet expectations, they were more likely to report poorer functional and psychological status at baseline, higher levels of learned helplessness, more pain and shorter physician visits in unadjusted analysis. Followed longitudinally, those reporting unmet expectations had an increase in pain score whereas those who did not had a slight decrease in pain $(P=0.002){ }^{23}$

With regard to satisfaction with therapy, Wolfe and Michaud conducted a large, cross-sectional survey of more than 6000 subjects with RA in the US to explore patients' acceptance and satisfaction with their current therapy (both biologic and non-biologic DMARDs), willingness to alter and reasons for not changing therapy. ${ }^{24}$ Subjects were enrollees of a longitudinal cohort and no additional education on specifics of alternative therapy was provided as part of this study. Overall, $77.3 \%$ of subjects were very satisfied or somewhat satisfied with their medications. Nearly three quarters of the patients reported not wanting to risk side effects of new medications, and $35.7 \%$ did not want to take treatments which required injections or ivs (the biologic DMARDs). The authors found very weak associations between measures of function, RA severity, and degree of satisfaction with control of their RA. They note that most RA patients in this study were satisfied with their current therapy despite many patients with abnormal scores on function and disease activity. However, they did report a small, but statistically significant difference in satisfaction among current biologic DMARD users and non-biologic users with the non-biologic users slightly more satisfied with their current treatment. In examining potential predictors of unwillingness to change therapy in this cohort, belief that RA control was adequate (odds ratio $[\mathrm{OR}]=6.8)$ and fear of side effects $(\mathrm{OR}=4.4)$ were the top predictors, adjusting for sociodemographic and RA factors. ${ }^{24}$

In a qualitative study done in the UK in 2004, Marshall and colleagues specifically asked a small group of RA patients $(n=19)$ about their experiences and views of $2 \mathrm{TNF}$ inhibitor therapies (infliximab and etanercept). ${ }^{19}$ The median RA disease duration of this group was 11 years, but average length of time on the TNF inhibitors was not reported. Patients expectations of treatment varied from low ("Not really expecting anything") to desperation ("literally to go for anything that's available") to higher expectations ("I'm going to be cured with in a couple of months"). The experience with these two biologic DMARDs was overall very positive: "marvelous", "thrilled to bits", "it's like being a normal person." The negative experiences related to lack of effect or side effects, yet there was little concern about the medications being a newer class of drug. Patients were aware of the high cost of the drugs and reported anxiety over the process of qualifying for the medication in the UK. ${ }^{19}$

A 2008 prospective study in Spain conducted on 198 subjects initiating therapy with infliximab assessed patient expectations with regard to treatment efficacy through a series of questions at multiple time points, including at baseline, 2, 6 and 14 weeks. After 2 weeks, $90 \%$ of patients reported that their expectations for treatment had been met and for $50 \%$, expectations were surpassed. Patients satisfied with treatment was $19.4 \%, 76.9 \%$ and $85.5 \%$ at baseline, 2 weeks and 14 weeks respectively. ${ }^{21}$

An example of patients' views differing from those of their rheumatologists is found in a 2008 qualitative study by van Tuyl et al in the Netherlands. ${ }^{20}$ While not directly assessing perspectives on biologic therapy, the objective of this study was to investigate opinions and beliefs of both physicians and patients in regard to COBRA (combination therapy in early rheumatoid arthritis) therapy through focus groups and in-depth interviews. COBRA consists of a stepdown combination therapy of methotrexate, sulfasalazine and high dose prednisolone which is tapered over 6 weeks from $60 \mathrm{mg}$ to $7.5 \mathrm{mg}$ daily. The striking finding in this study is how discordant physicians' views were from the patients. Physicians perceived potential practical problems 
with the therapy as well as negative emotions from patients and therefore were reluctant to prescribe the combination. One physician stated: "The patient leaves the room and says: 'this doctor is completely nuts. I enter with pain in my wrist and I leave with 8 different kinds of tablets!'”. Patients were much more positive: "I started with methotrexate, four tablets, well it gradually became more, and I thought 'give me as much as possible', because I really revived.” Patients' expectations of treatment were fairly uniform: less pain, improved function and quality of life. They also held trust in physician as being very important. ${ }^{20}$

In summary, patient satisfaction with their current RA treatment was quite high and willingness to change therapy to better control disease activity or improve function was curtailed by fear of side effects. With regard to biologics, specifically, patient expectations were variable, with some patients placing very high expectations on these therapies.

\section{Adherence and biologic therapies in RA}

Treatment adherence in arthritis has been reported to be between $30 \%$ and $78 \% .{ }^{25}$ While the descriptive terms of medication-taking present challenges in that they can sometimes be viewed as paternalistic, ${ }^{26}$ this review will use the terms "adherence," meaning the patient takes a medication according to the prescription, and "medication persistence," time from initiation to discontinuation of the treatment. ${ }^{27}$ In addition to variations on the definitions of terms, the methods for measuring adherence and persistence also vary but will not be debated in this review. First, the

Table 2 Treatment adherence/survival for biologic DMARDs in rheumatoid arthritis

\begin{tabular}{|c|c|c|c|c|c|}
\hline Author & Year, Country & Medication & $\begin{array}{l}\text { Study } \\
\text { size }(n=)\end{array}$ & $\begin{array}{l}\text { Adherence } \\
\text { evaluation }\end{array}$ & $\begin{array}{l}\text { Adherence or } \\
\text { survival (\%) }\end{array}$ \\
\hline \multirow[t]{3}{*}{ Flendrie $^{31}$} & 2003, Netherlands & Adalimumab & 94 & electronic registry & 73 \\
\hline & & Infliximab & 83 & & 66 \\
\hline & & Etanercept & 14 & & 74 \\
\hline Chung ${ }^{30}$ & 2003, Canada & Infliximab & 163 & chart review & 70.8 \\
\hline \multirow[t]{2}{*}{ Harley ${ }^{28}$} & 2003, USA & Infliximab & $|4|$ & claims data & $80.9^{b}$ \\
\hline & & Etanercept & 853 & & $68.4^{\mathrm{b}}$ \\
\hline Wendling ${ }^{29}$ & 2005, France & Infliximab & 41 & physician assessment & 74 \\
\hline \multirow[t]{3}{*}{ Zink $^{32}$} & 2005, Germany & Infliximab & 343 & physician assessment & 65.4 \\
\hline & & Etanercept & 511 & & 68.6 \\
\hline & & Anakinra & 70 & & 59 \\
\hline \multirow[t]{4}{*}{ Kristensen ${ }^{33}$} & 2006, Sweden & Infliximab & 50 & physician assessment & 47 \\
\hline & & Etanercept & 128 & & 74 \\
\hline & & Infliximab + MTX & 339 & & 69 \\
\hline & & Etanercept + MTX & 100 & & 89 \\
\hline \multirow[t]{7}{*}{ Grijalva $^{27}$} & 2007, USA & Infliximab & 75 & claims data & $85^{c}$ \\
\hline & & Adalimumab & 120 & & $134^{c}$ \\
\hline & & Etanercept & 374 & & $175^{\mathrm{c}}$ \\
\hline & & Anakinra & 72 & & $156^{c}$ \\
\hline & & Infliximab + MTX & 98 & & $155^{\mathrm{c}}$ \\
\hline & & Adalimumab + MTX & 107 & & $219^{c}$ \\
\hline & & Etanercept + MTX & 262 & & $147^{c}$ \\
\hline \multirow[t]{6}{*}{ Hetland ${ }^{48}$} & 2008, Denmark & All biologics & & & \\
\hline & $2000 / 2001$ & Inflix/eta/ada/other & $87 / 13 / 0 / 0$ & & 73 \\
\hline & 2002 & Inflix/eta/ada/other & $95 / 2 / 3 / 0$ & & 62 \\
\hline & 2003 & Inflix/eta/ada/other & $49 / 23 / 25 / 3$ & & 67 \\
\hline & 2004 & Inflix/eta/ada/other & $36 / 31 / 33 / 0$ & & 70 \\
\hline & 2005 & Inflix/eta/ada/other & $34 / 18 / 46 / 2$ & & 69 \\
\hline
\end{tabular}

Notes: ${ }^{a} \mathrm{At} 12$ months unless otherwise specified; ${ }^{\mathrm{C} C o m p l i a n c e}$ with $\geq 80 \%$ expected doses; ${ }^{\mathrm{T}}$ This number reflects the median persistence of the medication in days. Abbreviations: MTX, methotrexate; inflix, infliximab; eta, etanercept; ada, adalimumab. 
data on adherence and persistence will be summarized (Table 2), and then predictors of treatment adherence will be explored.

Harley and colleagues evaluated claims data on 2662 RA patients residing in the US with the objective of examining treatment adherence with 2 TNF inhibitors, infliximab (administered intravenously) and etanercept (self-administered subcutaneously) between July 1998 and December $2000 .{ }^{28}$ Of the 141 subjects on infliximab, $80.9 \%$ had compliance with at least $80 \%$ of the expected doses compared with $68.4 \%$ of the 853 subjects on etanercept. They also examined adherence to oral methotrexate and found that $63.7 \%$ of the 1668 subjects were adherent with at least $80 \%$ of expected doses. They did not examine predictors of adherence and it should also be noted that Centocor, the manufacturer of Remicade ${ }^{\circledR}$ (infliximab), was involved in the preparation of the manuscript and may have biased the results toward infliximab. ${ }^{28}$

The timing of the availability of TNF inhibitors varied between Europe and the US with etanercept being the first available in the US and infliximab was the first available in France. A study by Wendling et al examined continuation rates of infliximab in France from March 2000 through June 2003. ${ }^{29}$ Forty-one patients were followed for a minimum of 6 months. Treatment continuation rates were as follows: $82 \%$ at 6 months, $74 \%$ at 12 months, $67 \%$ at 24 months and $20 \%$ at 36 months. Throughout this study period, 14 (34\%) discontinued treatment (reasons included escape phenomenon, allergy, ineffectiveness, poor compliance, infection, and pregnancy). ${ }^{29}$ The continuation rates at 12 and 24 months for infliximab in this study mirror those of other studies done in Canada $(70.8 \%$ and $63.4 \%$ at 12 and 24 months, respectively), ${ }^{30}$ France (70\% at 24 months), and the Netherlands (66\% at 12 months). ${ }^{29,31}$

A 2005 prospective study in Germany by Zink and colleagues examined the drug continuation rates after 12 months in 511 subjects on etanercept (68.6\%), 343 on infliximab (65.4\%) and 70 on anakinra (59\%) compared to 599 subjects on non-biologic DMARDs. ${ }^{32}$ Treatment continuation was more likely for those who were on combinations of a biologic and a non-biologic DMARD. Predictors of premature termination of therapy with a biologic were number of prior DMARDs (hazard ratio $[\mathrm{HR}]=1.09$, $95 \%$ confidence interval [CI] 1.10 to 1.18 ), rheumatoid factor $(\mathrm{HR}=1.53,95 \% \mathrm{CI} 1.09$ to 2.16$)$ and greater age $(\mathrm{HR}=1.01$, 95\% CI 1.00 to 1.02). ${ }^{32}$ Another study performed in Sweden confirmed that concomitant use of a non-biologic DMARD (such as methotrexate) with biologic therapy can protect against premature termination with a biologic perhaps due to improved efficacy. ${ }^{33}$ Kristensen and colleagues performed a prospective study between 1999 and 2004 on 1161 biologic naïve patients to investigate predictors associated with premature TNF inhibitor treatment termination. They reported data at 1, 4 and 5 years. In comparison to prior studies cited in this review, only the 1-year data are presented here. Adherence at 1 year is as follows: combination of infliximab plus methotrexate: $69 \%$; etanercept plus methotrexate: $89 \%$; infliximab monotherapy: $47 \%$; etanercept monotherapy: $74 \%$. Other predictors of premature treatment termination in this study included low c-reactive protein level, older age, greater disability, and higher previous number of DMARDs. ${ }^{33}$

In summary, compared to prior ranges of adherence to medication in RA (including non-biologic DMARDs), ${ }^{25}$ adherence to the TNF inhibitors is fairly high. In addition, studies show that combinations of non-biologic and biologic DMARDs demonstrated the highest rates of adherence.

\section{Medication beliefs and predictors of treatment adherence in RA}

Several studies have more closely examined factors which may predict adherence to treatment in RA, from the financial cost to sociodemographic and psychological characteristics, including beliefs about medication. Patient beliefs related to the necessity of medication have been shown to be associated with adherence ${ }^{34}$ and medication beliefs among subjects with RA have been shown to vary among different ethnic groups. ${ }^{25,35}$

Treharne and colleagues aimed to investigate the effects of psychosocial factors on adherence to medication in $85 \mathrm{RA}$ patients in an outpatient setting in England. ${ }^{36}$ The mean age was 59 with mean disease duration of 10 years. The most commonly prescribed DMARD was methotrexate (58\%), and no details on biologic therapy were reported. Overall adherence to medication in this study was quite high with $94.2 \%$ and $90.6 \%$ responding "never" or "rarely" to how often participants forgot to take their medication and how often they miss out or adjust a dose of medication. In a hierarchical regression model, total number of medications, perceptions of specific necessity of their medications and their (lack of) beliefs about the general overuse of medications explained up to $64 \%$ of the variance in adherence with rheumatology medications..$^{36}$ This study reinforces the importance of understanding patients' attitudes toward treatment, and involving them in shared decision making to ultimately improve adherence. While not directly assessing beliefs about biologic therapies in RA, one could extrapolate 
these results to all medications used to treat this chronic, debilitating disease.

Another cross-sectional study from the UK evaluated 344 RA patients in the form of a questionnaire with regard to medication beliefs. ${ }^{34}$ Neame and Hammond report that most (74.3\%) of the respondents agreed or strongly agreed that their RA medications were necessary for their health (93\% of patients reported taking a DMARD). However, almost half (47.4\%) expressed concern over potential adverse consequences. The authors used an adaptation of the Beliefs about Medicines Questionnaire (BMQ) which consists of two five item scales which capture the two core beliefs held by patients: 1) the necessity for medications to maintain health (necessity score) and 2) concerns about the potential side effects of taking medications (concern score). ${ }^{34,36}$ They found that greater levels of pain, fatigue, and physical disability were associated with greater belief in the necessity of medications as well as greater concerns. In terms of the relationship between adherence and beliefs, the necessity scores for the adherent were not significantly different than the non-adherent. However, there was a difference in concern scores between the two groups with the mean score for the adherent group being significantly lower than for the non-adherent $(P=0.002){ }^{34}$

A US-based study examined adherence and predictors of adherence in an underserved, ethnically diverse cohort of 102 RA and lupus patients. ${ }^{25}$ As a group, nearly $80 \%$ reported that they "never" or "rarely" forgot to take medications; however upon comparing ethnic groups, African American patients had a lower adherence score than Whites and were more likely than Whites to discontinue medications on their own because they felt they were "not helping." In terms of the reasons why subjects missed or discontinued therapy, the most common reasons were running out of pills (37\%), forgetting (30\%), feeling depressed $(27 \%)$, being away from the home (27\%), and feeling well (25\%). African Americans and Hispanics were more likely than Whites to stop a medication because they felt it was harmful or toxic. ${ }^{25}$ The other differences between Whites and ethnic minorities were also found in the following reasons for missing medications: 1) asleep at dose time; 2) felt sick or ill; 3) depressed/overwhelmed; or 4) difficulties with scheduled times. One other study that explored ethnic differences in medication beliefs in RA and lupus was conducted in outpatient settings in the UK with equal numbers of patients of South Asian origin (3 or more grandparents born in India or Pakistan) and those of White British/Irish origin. ${ }^{35}$ This study found that patients of South Asian origin believed that medications in general were more overused and more harmful compared to patients of White British/Irish origin. The patients of South Asian origin also expressed more concern over DMARDs. ${ }^{35}$

Given the significant difference in cost between the biologic DMARDs as compared to the non-biologic DMARDs (Table 1), one must consider the impact of cost on adherence. Curkendall and colleagues studied the impact of patient out-of-pocket (OOP) expenditures on adherence and persistence with the biologic DMARDs using claims data from 2285 insured RA patients starting either etanercept or adalimumab during 2002-2004. ${ }^{37}$ Seventy-five percent of subjects started etanercept compared to $25 \%$ initiating therapy with adalimumab. The mean OOP cost per week was US\$7.84 \pm US $\$ 14.15$ and $92 \%$ of patients had OOP costs less than US $\$ 20$ per week. In unadjusted and adjusted analyses, higher OOP costs were associated with lower levels of adherence. Other variables associated with lower adherence in adjusted analysis were female gender and HMO insurance. Use of DMARDs prior to TNF inhibitor therapy and residence in the north-eastern US were both associated with higher adherence. With respect to persistence, patients with OOP costs greater than US\$50/ week were $58 \%$ more likely to stop therapy than those with lower OOP costs. ${ }^{37}$

In summary, subjects with prior DMARD use, strong beliefs in the necessity of medication for their health, and lower out of pocket costs had higher rates of adherence to RA medications, specifically biologic therapy. ${ }^{34,36,37}$ Concern for toxicity of medication was associated with lower rates of adherence, especially among ethnic minorities. ${ }^{25,38}$

\section{Patient preference for biologic therapies in RA}

The first two studies to examine patient preference for biologic therapies in RA were published in 2004. A meeting abstract from the European Union League Against Rheumatism described results from face to face interviews with 300 subjects from the European Union (EU) and 174 from the US. The objective of this study was to determine preferences for administration methods. Less than $25 \%$ of the EU and $18 \%$ of US subjects preferred intravenous over subcutaneous administration and over three-fourths of all patients preferred a "ready to use" prefilled syringe when compared to products requiring reconstitution or administration via iv every 8 weeks in hospital. ${ }^{39}$ In a separate study, Fraenkel and colleagues employed a method known as Adaptive Conjoint Analysis (ACA) to examine patient 
trade-offs between specific drug characteristics and identify individual patient preferences for specific DMARDs. ${ }^{40}$ The authors assessed the individual characteristics of treatment options by the value given it by the patient. Patients were then given a scenario, the "base case," which presented several treatment options using the maximum benefit of a medication taken from those benefits reported in the literature, a low probability of adverse effects and low equal monthly co-pays. For this base case, $95 \%$ of subjects preferred an option similar to etanercept over the other options. When they altered the scenario characterizing etanercept as being associated with rare $(0.1 \%)$ but serious infection risk, the number of patients selecting TNF inhibitors fell from $95 \%$ to $79 \%$. $^{40}$

While the efficacy of the three TNF inhibitors has not been rigorously evaluated in head to head trials comparing all 3 drugs, the route of administration and frequency differs and plays a role in decision-making for patients with RA. Williams and Edwards communicated the results of their study on patient preferences for TNF inhibitors in a 2006 letter to the editor. ${ }^{41}$ Of the 100 consecutive patients seen in an outpatient clinic during 2004, 50 were on a TNF inhibitor while the remaining 50 were on a conventional DMARD (10 subjects were then excluded due to lack of response on the questionnaire). Subcutaneous administration was preferred in both groups (41\% of those on anti-TNF; $52.5 \%$ not). The majority of subjects also preferred administration at home $(62.5 \%$ on anti-TNF; $52 \%$ not $)$. The authors did note that of those patients on anti-TNF therapy, their preferences corresponded with the route and frequency of administration of the drug they were currently taking, suggesting they were satisfied with their treatment. ${ }^{41}$

Among subjects with early RA ( $\leq 2$ years), GoekoopRuiterman and colleagues investigated patient preferences for their initial therapy in a randomized-controlled trial comparing 4 different treatment options conducted in the Netherlands (the BeST trial). ${ }^{42}$ The four treatment arms were as follows: 1) sequential monotherapy, beginning with methotrexate; 2) step-up combination therapy, starting with methotrexate; 3 ) initial combination therapy with methotrexate, sulfasalazine and prednisone; and 4) initial combination therapy with methotrexate and infliximab. It should be noted that after 2 years in the trial there were no significant differences in functional and clinical outcomes among the four groups, however those in the groups with initial combination therapy either with prednisone or infliximab had a more rapid improvement of function, and clinical signs and symptoms than the other groups.
Four hundred and forty out of 508 participants responded to the questionnaire on preferences. In terms of satisfaction, patients in group 4 (methotrexate and infliximab) stated their health improved much to very much since starting therapy (50\%, 56\%, 47\%, and $74 \%$ in groups 1 to 4 , respectively), and those in group 3 were the least satisfied (85\%, 88\%, $72 \%$ and $85 \%$ respectively). Pretrial preference was highest for group 4 with $62 \%$ in group 4 , and $22 \%$ in groups 1,2 , and 3 stating that treatment would have been their preference. Subjects were then asked if they were diagnosed with RA today, what treatment would they prefer: $21 \%$ would choose a treatment with a well-known antirheumatic drug, $19 \%$ would choose a combination without prednisone, $12 \%$ would choose a combination with prednisone, and $44 \%$ would chose a combination with the "newest" intravenous drug (infliximab). ${ }^{42}$

Chilton and Collett undertook a mixed methods approach to exploring preferences for TNF inhibitor therapy among RA patients in the UK. ${ }^{43}$ They sent questionnaires to 200 subjects on combination or triple therapy with non-biologic DMARDs and also conducted one on one interviews with 7 patients who had changed from one TNF inhibitor to another. The response rate for the questionnaire was $56 \%$. In addition to querying patients on their preferences for treatment, they also asked about patients' views on who should make decisions regarding therapy. A total of 45 (41\%) responded that the rheumatologist should decide, $7 \%$ preferred a joint decision, 33\% wanted to make the decision themselves, and 19\% were undecided. This demonstrates how widely patient preference for decision-making can vary. In terms of mode of administration of drug, almost half preferred to administer their own treatment (self-inject) vs a third who would not, and $22 \%$ were unsure. Younger patients were significantly more confident about self-administering treatment. Adalimumab was the most preferred of the TNF inhibitors by both the questionnaire respondents (47\% compared to $23 \%$ for infliximab and $4 \%$ for etanercept, $27 \%$ no preference) and for all of those interviewed. The interviewees preferred adalimumab because of the convenience of selfadministration and how it "would allow them to regain control of their lives." In addition to convenience, other factors which contributed to this treatment preference were not needing to prepare the medicine, reduced change of medication error, use of ready-to-use syringe with correct dose and not needing to travel to the hospital. However, among those who did choose infliximab (administered iv), "contact with patients/ meeting others" as well as "staff available if problems arose" were both significant factors influencing their choice. ${ }^{43}$ 
Constantinescu and colleagues explored whether or not treatment preferences in RA varied by race. ${ }^{44}$ Using the technique of adaptive conjoint analysis described earlier in this review, ${ }^{40}$ the authors studied 136 consecutive patients with RA (67 African American, 69 White). In unadjusted analysis, $51 \%$ of Whites vs $16 \%$ of African Americans preferred a more aggressive therapy $(P<0.0001)$. Married subjects and those who reported at least some college education had stronger preferences for aggressive therapy compared to those who were not married or had no college education. After adjustment for other covariates, race remained the strongest predictor of aggressive therapy (adjusted odds ratio $=11.2,95 \%$ CI 1.9 to 64.9 ). In another paper based on this study population, the same authors sought to determine how these two racial groups viewed risks and benefits related to medication as a possible explanation for the divergent preferences. ${ }^{45}$ They calculated values for the "relative importance" of each characteristic and noted that African Americans and Whites differed significantly in which particular treatment characteristics they viewed as having more relative importance than others. For instance, African Americans were most influenced by the theoretical risk of cancer (over other risks as well as treatment benefits) while Whites were most influenced by the likelihood of remission or likelihood of halting radiographic progression of disease. They also looked at risk aversion and found that $52 \%$ of African Americans were risk averse compared with $12 \%$ of Whites $(P<0.0001){ }^{45}$

In summary, patients prefer subcutaneous over iv administration of the TNF inhibitors and prefer to receive treatment at home. ${ }^{39,41,43}$ When given a choice among various options for therapy, including non-biologic or biologic DMARDs, patients chose a biologic or a combination therapy which included a biologic. ${ }^{40,42}$ The one study which explored racial differences found that African Americans preferred less aggressive therapy when compared with Whites and that they placed higher importance on risk over benefit when compared to Whites. ${ }^{44,45}$

In conclusion, treatment options for patients with RA continue to expand, creating opportunity for improved outcomes such as decreased pain, less disability and decreased mortality. However, with the introduction of newer therapies, patients as well as physicians are faced with increasingly complex decisions about how, when, and at what cost (both financially and with regard to toxicity) a medication will be initiated and continued. Patient preferences for TNF inhibitors need to be explored in more depth in populations at higher risk for poor communication with their physicians (those with low literacy, lower levels of education and immigrants) and at risk for incomplete understanding or misunderstanding of the risks and benefits of these potentially transforming medications.

Patients with RA prefer that education about the disease and its treatment be delivered on a one-to-one basis from health professionals. ${ }^{46}$ Patient preference and medication beliefs are associated with adherence ${ }^{47}$ and to ensure the best possible outcome for our patients with this destructive and debilitating disease, we must first provide comprehensive education regarding RA and its treatment options, elicit preferences, concerns about medications, and ensure that all patients possess an accurate and clear understanding of treatment risks and benefits to fully inform their decision making. A randomized, controlled trial of an educational and decision-making tool specifically designed for biologic DMARDs in an ethnically diverse population of adults with RA will help us discover the most effective way to communicate the complexities of these medications and also elicit preferences to allow for the maximum benefit for all patients.

\section{Acknowledgment}

The author would like to thank Rachel Kaiser, MD, MPH for her careful review of this manuscript.

\section{Disclosure}

The author discloses no conflicts of interest.

\section{References}

1. Sokka T, Abelson B, Pincus T. Mortality in rheumatoid arthritis: 2008 update. Clin Exp Rheumatol. 2008;26(5 Suppl 51):S35-S61.

2. Gabriel SE, Michaud K. Epidemiological studies in incidence, prevalence, mortality, and comorbidity of the rheumatic diseases. Arthritis Res Ther. 2009;11(3):229.

3. Kavanaugh A, Cohen S, Cush JJ. The evolving use of tumor necrosis factor inhibitors in rheumatoid arthritis. J Rheumatol. 2004;31(10): 1881-1884.

4. Donahue KE, Gartlehner G, Jonas DE, et al. Systematic review: comparative effectiveness and harms of disease-modifying medications for rheumatoid arthritis. Ann Intern Med. 2008;148(2):124-134.

5. Breedveld FC, Weisman MH, Kavanaugh AF, et al; The PREMIER study: A multicenter, randomized, double-blind clinical trial of combination therapy with adalimumab plus methotrexate versus methotrexate alone or adalimumab alone in patients with early, aggressive rheumatoid arthritis who had not had previous methotrexate treatment. Arthritis Rheum. 2006;54(1):26-37.

6. Klareskog L, van der Heijde D, de Jager JP, et al. Therapeutic effect of the combination of etanercept and methotrexate compared with each treatment alone in patients with rheumatoid arthritis: double-blind randomised controlled trial. Lancet. 2004;363(9410):675-681.

7. van der Heijde D, Klareskog L, Singh A, et al. Patient reported outcomes in a trial of combination therapy with etanercept and methotrexate for rheumatoid arthritis: the TEMPO trial. Ann Rheum Dis. 2006;65(3): $328-334$. 
8. van der Heijde D, Klareskog L, Rodriguez-Valverde V, et al. Comparison of etanercept and methotrexate, alone and combined, in the treatment of rheumatoid arthritis: two-year clinical and radiographic results from the TEMPO study, a double-blind, randomized trial. Arthritis Rheum 2006;54(4):1063-1074.

9. Bathon JM, Martin RW, Fleischmann RM, et al. A comparison of etanercept and methotrexate in patients with early rheumatoid arthritis. N Engl J Med. 2000;343(22):1586-1593.

10. Lee SJ, Kremer J, Kavanaugh A. Treatment disparity related to race/ethnicity and education in rheumatoid arthritis patients: comment on the article by Constantinescu, et al. Arthritis Rheum. 2009;61(8):1141-1142.

11. Jacobi CE, Mol GD, Boshuizen HC, Rupp I, Dinant HJ, Van Den Bos GA. Impact of socioeconomic status on the course of rheumatoid arthritis and on related use of health care services. Arthritis Rheum. 2003;49(4):567-573.

12. Pincus T, Keysor J, Sokka T, Krishnan E, Callahan LF. Patient questionnaires and formal education level as prospective predictors of mortality over 10 years in $97 \%$ of 1416 patients with rheumatoid arthritis from 15 United States private practices. J Rheumatol. 2004;31(2):229-234.

13. Iren UT, Walker MS, Hochman E, Brasington R. A pilot study to determine whether disability and disease activity are different in African-American and Caucasian patients with rheumatoid arthritis in St. Louis, Missouri, USA. J Rheumatol. 2005;32(4):602-608.

14. Jordan JM. Effect of race and ethnicity on outcomes in arthritis and rheumatic conditions. Curr Opin Rheumatol. 1999;11(2):98-103.

15. Katz JN. Preferences, disparities, and the authenticity of patient choices. J Rheumatol Suppl. 2003;68:12-14.

16. Smedley B, Stith AY, Nelson AR, editors. Unequal Treatment: Confronting Racial and Ethnic Disparities in Health Care. Washington, DC: Institute of Medicine; 2003.

17. Martin RW, Head AJ, Rene J, et al. Patient decision-making related to antirheumatic drugs in rheumatoid arthritis: the importance of patient trust of physician. J Rheumatol. 2008;35(4):618-624.

18. Saag KG, Teng GG, Patkar NM, et al. American College of Rheumatology 2008 recommendations for the use of nonbiologic and biologic disease-modifying antirheumatic drugs in rheumatoid arthritis. Arthritis Rheum. 2008;59(6):762-784.

19. Marshall NJ, Wilson G, Lapworth K, Kay LJ. Patients' perceptions of treatment with anti-TNF therapy for rheumatoid arthritis: a qualitative study. Rheumatology (Oxford). 2004;43(8):1034-1038.

20. van Tuyl LH, Plass AM, Lems WF, et al. Discordant perspectives of rheumatologists and patients on COBRA combination therapy in rheumatoid arthritis. Rheumatology (Oxford). 2008;47(10): 1571-1576.

21. Carbonell J, Badia X. Expectations, preferences and satisfaction of patients with rheumatoid arthritis receiving infliximab treatment. Med Clin (Barc). 2008;131(13):493-499.

22. Kjeken I, Dagfinrud H, Mowinckel P, Uhlig T, Kvien TK, Finset A. Rheumatology care: Involvement in medical decisions, received information, satisfaction with care, and unmet health care needs in patients with rheumatoid arthritis and ankylosing spondylitis. Arthritis Rheum. 2006;55(3):394-401.

23. Rao JK, Weinberger M, Anderson LA, Kroenke K. Predicting reports of unmet expectations among rheumatology patients. Arthritis Rheum 2004;51(2):215-221.

24. Wolfe F, Michaud K. Resistance of rheumatoid arthritis patients to changing therapy: discordance between disease activity and patients' treatment choices. Arthritis Rheum. 2007;56(7):2135-2142.

25. Garcia-Gonzalez A, Richardson M, Garcia Popa-Lisseanu M, et al. Treatment adherence in patients with rheumatoid arthritis and systemic lupus erythematosus. Clin Rheumatol. 2008;27(7):883-889.

26. Steiner JF, Earnest MA. The language of medication-taking. Ann Intern Med. 2000;132(11):926-930.

27. Grijalva CG, Chung CP, Arbogast PG, Stein CM, Mitchel EF Jr, Griffin MR. Assessment of adherence to and persistence on diseasemodifying antirheumatic drugs (DMARDs) in patients with rheumatoid arthritis. Med Care. 2007;45(10 Suppl 2):S66-S76.
28. Harley CR, Frytak JR, Tandon N. Treatment compliance and dosage administration among rheumatoid arthritis patients receiving infliximab, etanercept, or methotrexate. Am J Manag Care. 2003;9(6 Suppl): S136-S143.

29. Wendling D, Materne GE, Michel F, et al. Infliximab continuation rates in patients with rheumatoid arthritis in everyday practice. Joint Bone Spine. 2005;72(4):309-312.

30. Chung C, Mallon C, Spady B, Russell AS, Maksymovych WP. Survival Analysis of Treatment with Leflunomide, Combination Leflunomide/ Methotrexate, and Infliximab for Rheumatoid Arthritis in Routine Clinical Practice. Arthritis Rheum. 2003;48(Suppl 9):S334.

31. Flendrie M, Creemers MC, Welsing PM, den Broeder AA, van Riel PL. Survival during treatment with tumour necrosis factor blocking agents in rheumatoid arthritis. Ann Rheum Dis. 2003;62 Suppl 2:ii30-ii33.

32. Zink A, Listing J, Kary S, et al. Treatment continuation in patients receiving biological agents or conventional DMARD therapy. Ann Rheum Dis. 2005;64(9):1274-1279.

33. Kristensen LE, Saxne T, Nilsson JA, Geborek P. Impact of concomitant DMARD therapy on adherence to treatment with etanercept and infliximab in rheumatoid arthritis. Results from a six-year observational study in southern Sweden. Arthritis Res Ther. 2006;8(6):R174.

34. Neame R, Hammond A. Beliefs about medications: a questionnaire survey of people with rheumatoid arthritis. Rheumatology (Oxford). 2005;44(6):762-767.

35. Kumar K, Gordon C, Toescu V, et al. Beliefs about medicines in patients with rheumatoid arthritis and systemic lupus erythematosus: a comparison between patients of South Asian and White British origin. Rheumatology (Oxford). 2008;47(5):690-697.

36. Treharne GJ, Lyons AC, Hale ED, Douglas KM, Kitas GD. Predictors of medication adherence in people with rheumatoid arthritis: studies are necessary but non-validated measures of medication adherence are of concern. Rheumatology (Oxford). 2005;44(10):1330; author reply 1331.

37. Curkendall S, Patel V, Gleeson M, Campbell RS, Zagari M, Dubois R. Compliance with biologic therapies for rheumatoid arthritis: do patient out-of-pocket payments matter? Arthritis Rheum. 2008;59(10): 1519-1526.

38. Lim AY, Ellis C, Brooksby A, Gaffney K. Patient satisfaction with rheumatology practitioner clinics: can we achieve concordance by meeting patients' information needs and encouraging participatory decision making? Ann Acad Med Singapore. 2007;36(2): 110-114.

39. Jeffery M, Stokes A, Johnson K, Anderson D, Harper B, Hons Politics BA. Patient Preferences for Tumor Necrosis Factor (TNF) Antagonist. London, UK and Dallas, TX: The Research Partnership Ltd, Rheumatology Research International; 2004.

40. Fraenkel L, Bogardus ST, Concato J, Felson DT, Wittink DR. Patient preferences for treatment of rheumatoid arthritis. Ann Rheum Dis. 2004;63(11):1372-1378.

41. Williams EL, Edwards CJ. Patient preferences in choosing anti-TNF therapies-R1. Rheumatology (Oxford). 2006;45(12):1575-1576.

42. Goekoop-Ruiterman YP, de Vries-Bouwstra JK, Allaart CF, et al. Patient preferences for treatment: report from a randomised comparison of treatment strategies in early rheumatoid arthritis (BeSt trial). Ann Rheum Dis. 2007;66(9):1227-1232.

43. Chilton F, Collett RA. Treatment choices, preferences and decisionmaking by patients with rheumatoid arthritis. Musculoskeletal Care. 2008;6(1):1-14.

44. Constantinescu F, Goucher S, Weinstein A, Fraenkel L. Racial disparities in treatment preferences for rheumatoid arthritis. Med Care. 2009;47(3):350-355.

45. Constantinescu F, Goucher S, Weinstein A, Smith W, Fraenkel L. Understanding why rheumatoid arthritis patient treatment preferences differ by race. Arthritis Rheum. 2009;61(4):413-418.

46. Barlow JH, Cullen LA, Rowe IF. Educational preferences, psychological well-being and self-efficacy among people with rheumatoid arthritis. Patient Educ Couns. 2002;46(1):11-19. 
47. van den Bemt BJ, van Lankveld WG. How can we improve adherence to therapy by patients with rheumatoid arthritis? Nat Clin Pract Rheumatol. 2007;3(12):681

48. Hetland ML, Lindegaard HM, Hansen A, et al. Do changes in prescription practice in patients with rheumatoid arthritis treated with biological agents affect treatment response and adherence to therapy? Results from the nationwide Danish DANBIO Registry. Ann Rheum Dis. 2008;67(7):1023-1026.
49. Rheumatoid Arthritis Medicines: A Guide for Adults. AHRQ Pub. No. 08-EHC004-2A. April 2008. Agency for Healthcare Research and Quality. Rockville, MD

Patient Preference and Adherence

\section{Publish your work in this journal}

Patient Preference and Adherence is an international, peer-reviewed, open access journal that focusing on the growing importance of patient preference and adherence throughout the therapeutic continuum. Patient satisfaction, acceptability, quality of life, compliance, persistence and their role in developing new therapeutic modalities and compounds to optimize clinical outcomes for existing disease states are major areas of interest. This journal has been accepted for indexing on PubMed Central. The manuscript management system is completely online and includes a very quick and fair peer-review system. Visit http://www.dovepress.com/ testimonials.php to read real quotes from published authors.

Submit your manuscript here: http://www.dovepress.com/patient-preference-and-adherence-journal 